\title{
Electro-catalytic Reduction of Aqueous Nitrates using Cu-Sn and Cu-Pd Cathodes
}

\author{
Bernd Weber ${ }^{1, *}$, Alma Chávez ${ }^{2}$, Ernst A. Stadlbauer ${ }^{3}$ \\ ${ }^{1}$ Faculty of Engineering, Autonomous University of the State of Mexico, Cerro de Coatepec s/n Col. \\ San Buenaventura, C.P. 50130, Toluca, State of Mexico, Mexico. \\ ${ }^{2}$ Institute of Engineering, National Autonomous University of Mexico, Av. Universidad 3000, Col. \\ Copilco el alto, C.P. 04510, Coyoacán, Mexico City, Mexico. \\ ${ }^{3}$ Department of Math, Natural Science and Computer Science, University of Applied Sciences THM, \\ Campus Giessen, 35390 Giessen, Germany. \\ *E-mail: bweber@uaemex.mx
}

doi: $10.20964 / 2019.01 .21$

Received: 18 July 2018 / Accepted: 14 September 2018 / Published: 30 November 2018

\begin{abstract}
Water treatment systems are used globally to reduce environmental impacts or to provide potable water, thus fulfilling established water quality standards. Electrocatalytic nitrate removal is a promising tool to address upcoming problems related to nitrate contamination. This study compares the employment of a low cost $\mathrm{CuSn} 6$ based catalyst with a noble metal $\mathrm{Cu}-\mathrm{Pd}$ catalyst in a laboratory and a continuously operating pilot apparatus to treat nitrate contaminated water from a well. In contrast with common applications, a saturated carbonic acid was used as the anolyte solution, which stabilized the $\mathrm{pH}$ in the anode compartment as well as in the cathode compartment. The best performance, as determined by nitrate removal and nitrogen transfer into the gas phase, was reached with a specific current of $1.16 \mathrm{~A}$ $\mathrm{m}^{-2}$ for the laboratory apparatus and $1.53 \mathrm{~A} \mathrm{~m}^{-2}$ for the pilot plant apparatus. However, other parameters such as $\mathrm{pH}$ (influenced by anolyte solution) and catalyst selection also had an impact on the nitrate reduction performance with the consequence that process optimization should be realized on-site while running a pilot plant. Process gas analysis by mass spectroscopy revealed the presence of hydrogen, which suggests that a combination of the system with heterogeneous catalysts should be used for additional nitrogen reduction at potential free surfaces.
\end{abstract}

Keywords: Copper-tin electrode; Carbonic acid; Palladium-Copper Catalyst; Groundwater

\section{FULL TEXT}

(C) 2019 The Authors. Published by ESG (www.electrochemsci.org). This article is an open access article distributed under the terms and conditions of the Creative Commons Attribution license (http://creativecommons.org/licenses/by/4.0/). 